\title{
Efficacy of screening using annual fecal immunochemical test alone versus combined with one-time colonoscopy in reducing colorectal cancer mortality: the Akita Japan population-based colonoscopy screening trial (Akita pop-colon trial)
}

\author{
Hiroshi Saito $^{1,2}$. Shin-ei Kudo ${ }^{3}$. Noriaki Takahashi ${ }^{4,5} \cdot$ Seiichiro Yamamoto $^{6}$ - Kenta Kodama ${ }^{7}$ Koichi Nagata ${ }^{5,8}$. \\ Yuri Mizota $^{6} \cdot$ Fumio Ishida $^{3} \cdot$ Yasuo Ohashi $^{9}$
}

Accepted: 26 January 2020 /Published online: 7 February 2020

(C) The Author(s) 2020

\begin{abstract}
Purpose Screening programs using fecal occult blood testing help reduce mortality from colorectal cancer (CRC). Colonoscopy and colonoscopy combined with fecal occult blood testing are considered alternatives with higher sensitivity than fecal tests; however, to our knowledge, randomized controlled trials (RCTs) providing such evidence have not been reported. Therefore, this study aimed to compare screening using the fecal immunochemical test (FIT) combined with colonoscopy and FIT alone to evaluate the efficacy of colonoscopy screening in reducing CRC mortality.

Methods This multicenter, prospective, randomized, controlled study included average-risk individuals for CRC living in the study areas and aged 40-74 years. The exclusion criteria were history of CRC, hereditary non-polyposis CRC, familial adenomatous polyposis, inflammatory bowel diseases, history of cancer other than CRC within the past 5 years, and not expected to survive from comorbid illness. The intervention group underwent one-time colonoscopy and annual FIT, while the control group underwent annual FIT. The primary endpoint was mortality from CRC, while the secondary endpoints were cumulative incidence of invasive CRC, advanced CRC (invasion into the muscle layer or deeper), invasive cancer and screening sensitivities and specificities of invasive CRC, whole CRC, advanced neoplasia, and prevalence of adverse events. The intervention and control groups comprised 4876 and 4875 participants, respectively.

Conclusion This explanatory RCT evaluated the efficacy of colonoscopy screening by valid statistical inference based on randomization. Data on adverse events from this kind of screening are necessary when considering implementation of future screening programs.
\end{abstract}

Trial registration UMIN Clinical Trials Registry, number UMIN000001980.

Keywords Colonoscopy screening · Fecal immunochemical occult test · Randomized controlled trial · Colorectal cancer · Mortality $\cdot$ Incidence

Hiroshi Saito

hrsaito@med.pref.aomori.jp

1 Aomori Prefectural Central Hospital, 2-1-1 Higashi-Tsukurimichi, Aomori 030-8553, Japan

2 Division of Medical Support and Partnership, Center for Cancer Control and Information Services, National Cancer Center, Tokyo, Japan

3 Digestive Disease Center, Showa University Northern Yokohama Hospital, Yokohama, Japan

4 Division of Screening Assessment and Management, Center for Public Health Sciences, National Cancer Center, Tokyo, Japan
5 Cancer Screening Center, National Cancer Center Hospital, Tokyo, Japan

6 Center for Cancer Control and Information Services, National Cancer Center, Tokyo, Japan

7 Department of Gastroenterology, Japanese Red Cross Fukushima Hospital, Fukushima, Japan

8 Department of Gastroenterology, Fukushima Medical University School of Medicine, Fukushima, Japan

9 Department of Integrated Science and Engineering for Sustainable Society, Chuo University, Tokyo, Japan 


\section{Introduction}

Colorectal cancer (CRC) has one of the largest disease burdens among individuals living in developed countries worldwide [1]. A similar trend was observed in Japan [2]. CRC is the third leading cause of cancer-related death in men and the first leading cause of cancer-related death in women in Japan [2].

Robust evidence has been accumulated from four representative randomized controlled trials (RCTs) reporting the efficacy of the guaiac-based fecal occult blood test; a reduction in CRC mortality was reported [3-6]. In addition, screening using the fecal immunochemical test (FIT) for occult blood was considered better due to its increased sensitivity to detect cancer and advanced neoplasia than that of the guaiac-based test [7].

To increase the efficacy of screening programs, endoscopy has been chosen as the candidate screening test. Colonoscopy has been the dominant method for CRC screening in the USA [8]. The US Preventive Services Task Force has recommended colonoscopy as the screening method for CRC in averagerisk, asymptomatic adults aged 50-75 years [9]. However, while several RCTs evaluating the efficacy of sigmoidoscopy screening have demonstrated reduced mortality from and incidence of CRC [10-13], there is limited evidence supporting the efficacy of colonoscopy screening [14].

A few RCTs have evaluated the efficacy of colonoscopy screening [15-18]; however, most had a management design [15]. Randomization was conducted before obtaining informed consent. Under such a design, it is not possible to evaluate the efficacy of colonoscopy screening by valid statistical inference based on randomization. To investigate the efficacy of colonoscopy screening without any serious bias, an explanatory RCT [15], in which randomization is performed only for participants who provide informed consent, is required.

Therefore, we conducted a multicenter, prospective RCT to evaluate the effect on mortality reduction of the screening program using one-time colonoscopy combined with annual FIT compared to the program using annual FIT only, which is the program implemented in Japan. Recruitment was terminated at the end of March 2017 after achieving the numerical participant target. Herein, we report the study design.

\section{Methods}

\section{Trial design}

As screening programs using annual FIT were implemented nationwide in 1992 in Japan, it is not feasible to create a control group in which patients did not undergo CRC screening programs. Even if it was possible, it might not be ethical to include a control group of patients who did not undergo screening tests. Under these circumstances, FIT was provided to both groups, and colonoscopy was added to FIT as an intervention (intervention group). The study participants were assigned in a 1:1 ratio to the study arm and control arm. The trial was registered with the UMIN Clinical Trials Registry (number UMIN000001980).

\section{Hypothesis and objectives}

The hypothesis is that addition of one-time colonoscopy to the screening program using annual FIT will result in a higher reduction in mortality from $\mathrm{CRC}$ than the existing program using annual FIT only. The main objective was to demonstrate that the screening program using one-time colonoscopy and annual FIT is more effective than the program using annual FIT only in terms of reduction in CRC mortality.

\section{Study organization}

Three independent units were set up to manage the study. The executive office for the study was placed at Showa University and the secretariat office at National Cancer Center. In addition, the data center was set at the Japan Clinical Research Supporting Unit, which has been engaged in data center activity for many clinical trials since 2001 . The executive office was responsible for managing the entire study and dispatching gastroenterologists, who performed colonoscopy screening. The secretariat office was responsible for the design of the study as well as the follow-up and management of the study including quality assurance. Data on screening tests and diagnostic follow-up results were collected by offices at the screening site set in the two city offices and sent to the data center through an electrical transmission system. The data were exclusively kept within the data center.

\section{Study population and participants (Table 1 and Fig. 1)}

The study was originally conducted in the Semboku City in Akita Prefecture in 2009 and was expanded to Daisen City in 2011. The number of inhabitants aged 40-74 years in each city was 15,267 in 2009 and 43,135 in 2011 [19]. In both cities, population-based-organized CRC screening programs had been implemented since 1992 as a public health policy.

Study participants aged 40-74 years from both cities were enrolled. Asymptomatic, average-risk participants were chosen among those who submitted FIT kits. Average risk subjects were defined as those who were healthy and asymptomatic with regard to symptoms related to CRC. FIT kits were previously sent to those who agreed to participate in the CRC screening program organized by the municipalities. Individuals with a history of CRC, with hereditary nonpolyposis CRC, with familial adenomatous polyposis, with 
Table 1 Eligibility criteria of study subjects

I. Inclusion criteria

1. Inhabitants aged 40-74 years at enrollment

II. Exclusion criteria

1. Those who had previous history of colorectal cancer (CRC) including cancer in situ

2. Those with familial polyposis or hereditary non-polyposis CRC and those with inflammatory bowel diseases

3. Those who developed malignant tumors other than CRC within the past 5 years

4. Those who have serious morbidities and are not expected to survive for more than 5 years

inflammatory bowel diseases (ulcerative colitis or Crohn's disease), with a history of cancer other than CRC within the past 5 years, and who were not expected to survive from comorbid illness for more than 5 years (Table 1 ) were excluded. Individuals who had severe comorbidity were defined as those who were forbidden to undergo endoscopy by their attending physicians due to their illness such as cardiovascular or respiratory diseases of a severe degree.

Screening history was not considered during patient selection. The most recent screening test modality and its duration were identified by administering a questionnaire at baseline and were recorded in the database at the data center. The questionnaire included information on lifestyle factors such as diet and physical activities and psychological factors. Colonoscopy screening performed outside the study and diagnostic colonoscopy were also identified using the questionnaire and were included in the analysis of the study results.

Participants were required to provide written informed consent after receiving an explanation about the study and the possible advantages and disadvantages from participating the study.

\section{Randomization}

Randomization was performed using a sealed envelope with instructions for each of the two study arms assigned. Randomization procedures were explicitly designed at the data center. Block assignment was randomly generated on computer for each of the two study areas. In this study, the envelope method was performed based on requirements in order to preserve adequate allocation sequence concealment [20]. Key points of the envelope method in this study were as follows:

1. Sequentially numbered, opaque, and sealed envelopes were used. Just after allocation instruction was created based on computer-generated random numbers, it was enclosed in the envelope and sealed.

2. The envelope was opened by the trained staff, who explained the study to the study participants after informed consent was obtained.

3. The envelopes were opened strictly in the order of the serial numbers created for the envelopes.

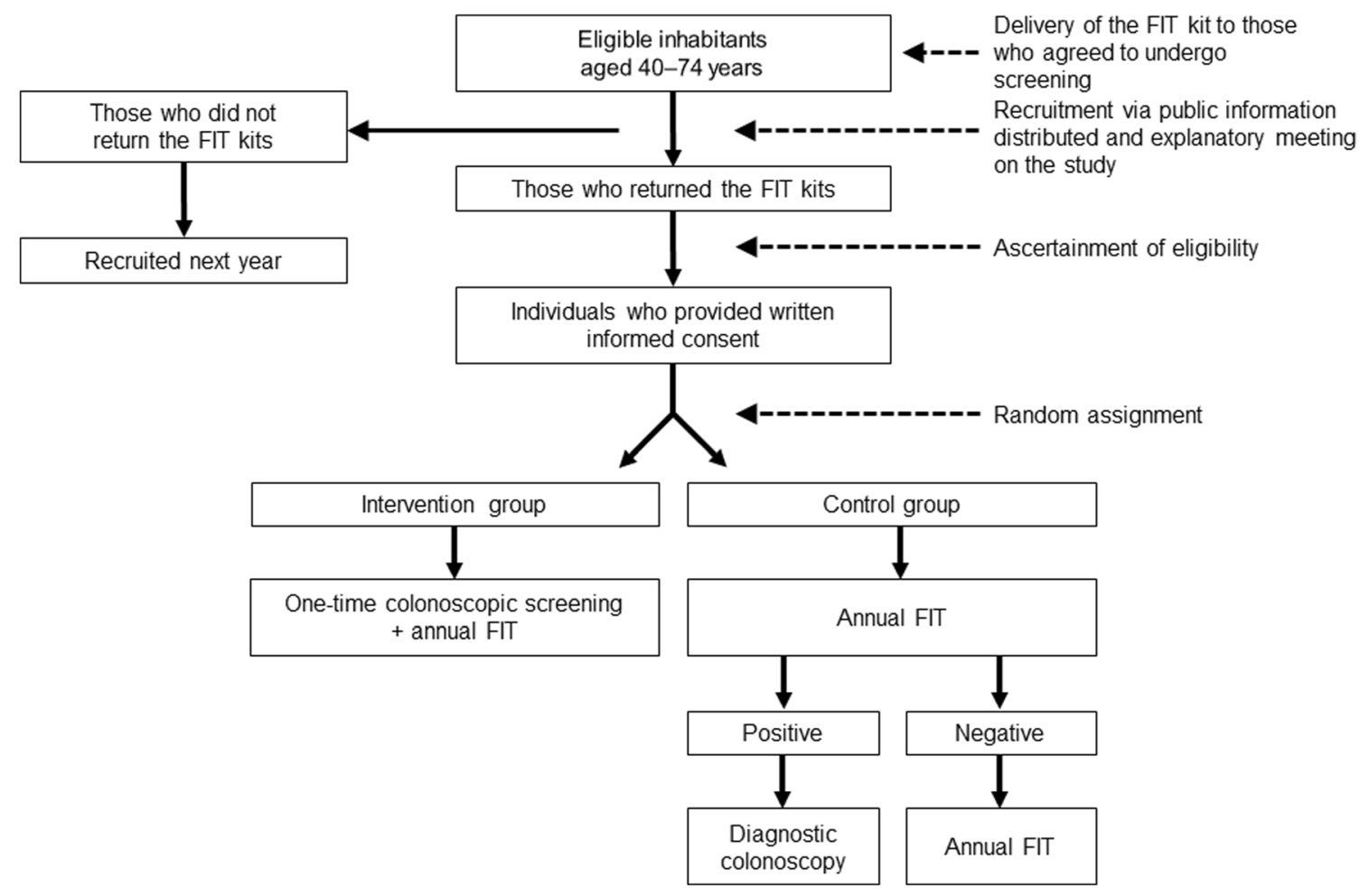

Fig. 1 Flow chart of participant selection. FIT, fecal immunochemical test 
4. All the envelopes were archived so that we could investigate if any mistakes had occurred during the procedure.

5. All the sequential numbers of the opened envelopes were registered on the electronic data capture system for a later validation of the allocation.

The dates of allocation were verified to be the same days as those of informed consent on all subjects. In addition, it was confirmed using a written record that all the envelopes were opened sequentially in the order of the serial numbers created for each envelope. Thus, the randomization was appropriately done in this study.

In this study, the risk-stratified allocation was not used, because the protocol committee of this study, which involved expert biostatisticians, concluded that it was not necessary for this study if the target numbers of subjects (5000 for each arm) could be recruited. Some variables related to the risk of CRC such as a history of preceding colonoscopy will be available with the questionnaire and used for comparison of the risk between the two arms.

\section{Intervention}

For those in the intervention group, one-time colonoscopy screening in addition to 2-day FIT was performed. For those in the control group, only FIT was performed. Patients in the intervention group were scheduled to undergo colonoscopy within 4 months of recruitment in the study. Colonoscopy was performed at Kakunodate Hospital or Akita Red Cross Hospital by trained endoscopists. Those individuals who were found to have cancers or adenomas $\geq 5 \mathrm{~mm}$ in diameter were treated on another day of screening colonoscopy. Minute lesions of $<5 \mathrm{~mm}$ in diameter primarily remained untreated.

Annual FIT was performed in both groups. Patients with positive FIT results underwent diagnostic colonoscopy within 3 months of the announcement of the FIT results primarily at Kakunodate Hospital, Akita Red Cross Hospital, or other hospitals, if they requested to undergo the procedure at a specific hospital where expert colonoscopists were available.

\section{Follow-up of study subjects}

Follow-up was conducted in two ways. First, the list of participants was obtained from the database of the resident registry annually to identify those who died and those who moved outside the two cities. The cancer registry was used to identify the incidence of CRC in the study cohort.

National Vital Statistics was also utilized to identify deceased individuals and causes of deaths among study subjects. The data center was responsible for performing those procedures. Second, the health status of each participant was identified by conducting an annual survey using a questionnaire sent to the participants via mail. This questionnaire was used for analyses of risk factors but could also be used as a complimentary method to identify conditions related to health status, including endpoints and the eligibility of each participant to remain in the study. The follow-up period was set at 10 years after enrollment. However, it could be extended adaptively to achieve significant results regarding relevant variables such as mortality and incidence.

Adverse events to be monitored were defined as disorders requiring treatment upon admission. All adverse events were reported to the data center and secretariat office. Among the events, those of a serious grade were reported to the secretariat office immediately after occurrence.

\section{End points}

CRC mortality was the primary endpoint; several secondary endpoints were employed: cumulative incidence of advanced CRC (cancer invaded into the muscle layer or deeper); cumulative incidence of invasive cancer; screening sensitivities and specificities toward invasive $\mathrm{CRC}$, whole $\mathrm{CRC}$, and advanced neoplasia; and prevalence of adverse events. Mortality and incidence data were obtained as previously described.

\section{Quality assurance of the RCT and screening}

\section{Quality assurance of management}

The secretariat office was responsible for educating the relevant staff at screening sites regarding issues related to the process of obtaining informed consent and the method for registering screening data. The staff at the data center played a central role in quality assurance by visiting the screening sites.

\section{Colonoscopy screening}

At Kakunodate Hospital, three gastroenterologists who were supposed to be dispatched from Showa University every 6 months were responsible for performing colonoscopy. Each colonoscopic procedure was performed by those gastroenterologists, who had performed more than 200 colonoscopic procedures before the study period. We aimed to evaluate the efficacy of screening colonoscopy program, which was feasible as population-based screening programs, and thus we also employed colonoscopists of nonexpert level in terms of experience. All participants who received colonoscopy screening did a full-cathartic bowel preparation, with polyethylene glycol electrolyte lavage solution for bowel preparation on the morning of the examination. Sedatives, analgesics, and muscle relaxants were used if patients requested them or if the gastroenterologists thought they were needed based on their clinical judgment. A repeat colonoscopy screening was performed in cases where the first screening 
was not completed. Pain was monitored after colonoscopy using a questionnaire, and data were used to examine the degree of pain from the examination.

\section{Diagnostic colonoscopy}

Possible hospitals other than the Kakunodate Hospital and Akita Red Cross Hospital were listed. The workshop for physicians and endoscopists was conducted in these hospitals to explain the outcome of the study (i.e., reporting of diagnostic colonoscopy results and adverse events related to the diagnostic and therapeutic procedures) and obtain cooperation for conducting this study.

\section{FIT}

FIT was performed at the Akita Foundation for Health Care according to the guidelines recommended by the Ministry of Health, Labour and Welfare [21]. The foundation was responsible for quality assurance of FIT.

\section{Statistical analysis of sample size}

There is limited evidence on the efficacy of endoscopic screening. However, two case-control studies that evaluated the efficacy of the rigid sigmoidoscopic screening or flexible sigmoidoscopic screening showed lower risk in individuals who had a history of screening than in those who did not $[22,23]$. One study using rigid sigmoidoscopy reported that the risk of death due to CRC after screening was 0.41 [95\% confidence interval (CI), 0.250.69] [22]. Among individuals whose most recent screening had been 9 to 10 years before, the odds ratio was 0.12 (95\% CI, 0.02 0.93 ). There was no reduction in the risk of dying from proximal colon cancer (odds ratio 0.96 ; 95\% CI, 0.61-1.50). The other study using flexible sigmoidoscopy and rigid sigmoidoscopy (approximately $60 \%$ of patients underwent sigmoidoscopy) reported the risk of 0.21 (95\% CI, 0.08-0.52) for dying from CRC [23]. As sigmoidoscopy could not detect cancers proximal to the sigmoid colon, the odds ratio of death due to cancer in the rectum and sigmoid colon was estimated to be 0.05 (95\% CI, 0.01-0.43) [23]. Consequently, the relative risk of 0.1 was hypothesized for the intervention group (90\% reduction in mortality compared with those who did not undergo screening). By contrast, the relative risk after FIT was reported to be $0.2-0.4$ in the casecontrol studies, and the relative risk for the control group was hypothesized to be 0.4 (60\% reduction compared with the group did not undergo screening) [24-28]. As this RCT was explanatory in nature and randomization was performed after obtaining informed consent, the rate of compliance to colonoscopy was assumed to be nearly $100 \%$. The sample size was computed assuming that the rate of compliance to colonoscopy was $100 \%$. Regarding FIT, individuals who submitted the FIT kits and those who eventually completed the screening test were recruited. It was considered appropriate to use the relative risk obtained from the case-control studies, which represents the risk in responders (in whom compliance was 100\%) compared with that in nonresponders.

Sample size was calculated based on the relative risks in each group and mortality data in Akita Prefecture and Semboku City in 1998-2002, which was the most recent mortality data available at the time of the study. The baseline mortality rate was $0.556 / 1000$ person-years. Calculations were performed by changing the relative risks of interventions and power of the trial. Sensitivity analyses were also performed by changing the mortality rate from $0.42 / 1000$ person-years to $0.70 / 1000$ person-years. The sample size calculated with the relative risk of 0.1 for the intervention group and 0.4 for the control group with a one-sided $p$ value of 0.05 and statistical power of $80 \%$ was 123,000 person-years in both groups. With a statistical power of $70 \%$, the necessary sample size was calculated to be 94,000 person-years for both groups. The numerical target for recruitment was set at 10,000, which can achieve a statistical power of $70 \%$ with 5 years of recruitment and another 7.5 years of follow-up. In actuality, we recruited 9751 subjects for 8 years (2009-2016), and an additional 6-years of follow-up until 2023 will achieve more than $70 \%$ power.

\section{Discussion}

We designed an RCT to compare the efficacy of the screening program using one-time colonoscopy combined with annual FIT and the program using annual FIT, which is the program currently implemented in Japan. A few ongoing RCTs are evaluating the efficacy of colonoscopy screening [15-18], but most of them have a management design. To evaluate the efficacy of colonoscopy screening by valid inference based on randomization, an explanatory RCT is necessary. This study is an explanatory RCT, which will be able to evaluate the efficacy of colonoscopy screening without serious bias. Accordingly, this study has a different significance from other ongoing RCTs due to its explanatory design [15-18]. We employed several secondary endpoints, such as cumulative incidence of advanced CRC, which are indirectly related to the efficacy of the screening. Data on those endpoints will help to evaluate efficacy. In addition to the evidence of efficacy, data on adverse events from colonoscopy screening will be important when considering the implementation of colonoscopy into future screening programs. However, there have been scarce data on adverse events from colonoscopy screening in an average-risk population; this study would provide data on the prevalence of adverse events in the populationbased screening program. Concerning colonoscopy experience of gastroenterologists, those of the nonexpert level were also involved. Indicators on colonoscopy performance such as cecal intubation rates, adenoma detection rates, and pain/ 
discomfort on colonoscopy will be evaluated according to colonoscopy experience of gastroenterologists.

The study has some limitations. There is uncertainty regarding validity of the target sample size due to lack of robust information for calculation. In addition, the sample size obtained might be insufficient because of low compliance to recruitment. The follow-up period should be adaptively changed in order to achieve results of statistical significance regarding relevant variables such as the mortality of CRC in the whole study population, which is monitored during follow-up.

In conclusion, we hereby report the design of an explanatory RCT, which is expected to provide important findings for efficacy and other issues vital to consideration on the implementation of screening colonoscopy as population-based screening for CRC.

Acknowledgments The authors would like to sincerely thank the staff of the offices at the screening site in Semboku and Daisen cities.

Funding information This study is supported by the Health Labour Sciences Research grants from the Ministry of Health, Labour and Welfare and the Practical Research for Innovative Cancer Control from the Japan Agency for Medical Research and Development (Grant Number JP19ck0106279).

\section{Compliance with ethical standards}

Ethical considerations This study was planned and designed according to the Helsinki Declaration. All researchers involved in this trial performed the study according to the declaration. As annual CRC screening had been performed in Japan, interventions for the study groups were decided based on the existing programs. This study was approved by the Institutional Review Boards (IRBs) of the National Cancer Center, Showa University, Akita Red Cross Hospital, and the Public Health Research Foundation; the IRB of Public Health Research Foundation was a surrogate IRB assigned to review the clinical activity conducted at Kakunodate Hospital, as they did not have an institutional IRB.

Open Access This article is licensed under a Creative Commons Attribution 4.0 International License, which permits use, sharing, adaptation, distribution and reproduction in any medium or format, as long as you give appropriate credit to the original author(s) and the source, provide a link to the Creative Commons licence, and indicate if changes were made. The images or other third party material in this article are included in the article's Creative Commons licence, unless indicated otherwise in a credit line to the material. If material is not included in the article's Creative Commons licence and your intended use is not permitted by statutory regulation or exceeds the permitted use, you will need to obtain permission directly from the copyright holder. To view a copy of this licence, visit http://creativecommons.org/licenses/by/4.0/.

\section{References}

1. Arnold M, Sierra MS, Laversanne M et al (2017) Global patterns and trends in colorectal cancer incidence and mortality. Gut 66(4): 683-691
2. Cancer Registry and Statistics. Cancer Information Service, National Cancer Center, Japan. https://ganjoho.jp/reg_stat/ statistics/dl/index.html. Accessed 5 Sep 2019 (in Japanese)

3. Mandel JS, Bond JH, Church TR, Snover DC, Bradley GM, Schuman LM, Ederer F (1993) Reducing mortality from colorectal cancer by screening for fecal occult blood. N Engl J Med 328(19): 1365-1371

4. Hardcastle JD, Chamberlain JO, Robinson MH, Moss SM, Amar SS, Balfour TW, James PD, Mangham CM (1996) Randomised controlled trial of faecal-occult-blood screening for colorectal cancer. Lancet 348(9040):1472-1477

5. Kronborg O, Fenger C, Olsen J, Jørgensen OD, Søndergaard O (1996) Randomised study of screening for colorectal cancer with faecal-occult-blood test. Lancet 348(9040):1467-1471

6. Faivre J, Dancourt V, Lejeune C, Tazi MA, Lamour J, Gerard D, Dassonville F, Bonithon-Kopp C (2004) Reduction in colorectal cancer mortality by fecal occult blood screening in a French controlled study. Gastroenterology 126(7):1674-1680

7. Van Rossum LG, van Rijn AF, Laheij RL et al (2008) Random comparison of guaiac and immunochemical fecal occult blood test for colorectal cancer in a screening population. Gastroenterology 135(1):82-90

8. Smith MA, Weiss JM, Potvien RE et al (2017) Insurance coverage for CT colonography screening: impact on overall colorectal cancer screening rates. Radiology 284(1):717-724

9. US Preventive Services Task Force, Bibbins-Domingo K, Grossman DC, Curry SJ et al (2016) Screening for colorectal cancer: US Preventive Services Task Force recommendation statement. JAMA 315(23):2564-2575

10. Atkin WS, Edwards R, Kralj-Hans I, Wooldrage K, Hart AR, Northover JM, Parkin DM, Wardle J, Duffy SW, Cuzick J, UK Flexible Sigmoidoscopy Trial Investigators (2010) Once-only flexible sigmoidoscopy screening in prevention of colorectal cancer: a multicentre randomised controlled trial. Lancet 375(9726):1624 1633

11. Segnan N, Armaroli P, Bonelli L, Risio M, Sciallero S, Zappa M, Andreoni B, Arrigoni A, Bisanti L, Casella C, Crosta C, Falcini F, Ferrero F, Giacomin A, Giuliani O, Santarelli A, Visioli CB, Zanetti R, Atkin WS, Senore C, SCORE Working Group (2011) Once-only sigmoidoscopy in colorectal cancer screening: follow-up findings of the Italian randomized controlled trial-SCORE. J Natl Cancer Inst 103(17):1310-1322

12. Schoen RE, Pinsky PF, Weissfeld JL, Yokochi LA, Church T, Laiyemo AO, Bresalier R, Andriole GL, Buys SS, Crawford ED, Fouad MN, Isaacs C, Johnson CC, Reding DJ, O'Brien B, Carrick DM, Wright P, Riley TL, Purdue MP, Izmirlian G, Kramer BS, Miller AB, Gohagan JK, Prorok PC, Berg CD, PLCO Project Team (2012) Colorectal-cancer incidence and mortality with screening flexible sigmoidoscopy. N Engl J Med 366(25):23452357

13. Holme Ø, Løberg M, Kalager M et al (2014) Effect of flexible sigmoidoscopy screening on colorectal cancer incidence and mortality. A randomized controlled trial. JAMA 312(6):606-615

14. Nishihara $\mathrm{R}, \mathrm{Wu} \mathrm{K}$, Lochhead $\mathrm{P}$, Morikawa $\mathrm{T}$, Liao $\mathrm{X}$, Qian ZR, Inamura K, Kim SA, Kuchiba A, Yamauchi M, Imamura Y, Willett WC, Rosner BA, Fuchs CS, Giovannucci E, Ogino S, Chan AT (2013) Long-term colorectal-cancer incidence and mortality after lower endoscopy. N Engl J Med 369(12):10951105

15. Kaminski MF, Bretthauer M, Zauber AG et al (2012) The NordICC study: rationale and design of a randomized trial on colonoscopy screening for colorectal cancer. Endoscopy 44(7):695-702

16. Quintero E, Castell A, Bujanda L et al (2012) Colonoscopy versus fecal immunochemical testing in colorectal-cancer screening. $\mathrm{N}$ Engl J Med 366(8):697-706 
17. Dominitz JA, Robe DJ, Robertson DJ et al (2017) Colonoscopy vs. fecal immunochemical test in reducing mortality from colorectal Cancer (CONFIRM): rationale for study design. Am J Gastroenterol 112(11):1736-1746

18. Bretthauer M, Kaminski MF, Loberg M et al (2016) Populationbased colonoscopy screening for colorectal cancer. A randomized clinical trial. JAMA Intern Med 176(7):894-902

19. The basic resident register population. The Ministry of Internal Affairs and Communications of Japan. http://www.soumu.go.jp/ main_sosiki/jichi_gyousei/daityo/jinkou_jinkoudoutai-setaisuu. html. Accessed 5 Sep 2019 (in Japanese)

20. Julian PT Higgins, Sally green. Cochrane handbook for systematic reviews of interventions version 5.1.0: 8.10.2 assessing risk of bias in relation to adequate or inadequate allocation sequence concealment. Cochrane. https://handbook-5-1.cochrane.org. Accessed 27 Dec 2019

21. National guidelines for population based cancer screening programs. Ministry of Health, Labour and Welfare. https://www. mhlw.go.jp/stf/seisakunitsuite/bunya/0000059490.html. Accessed 5 Sep 2019 (in Japanese)

22. Selby JV, Friedman GD, Quesenberry CP Jr et al (1992) A casecontrol study of screening sigmoidoscopy and mortality from colorectal cancer. N Engl J Med 326(10):653-657

23. Newcomb PA, Norfleet RG, Storer BE, Surawicz TS, Marcus PM (1992) Screening sigmoidoscopy and colorectal cancer mortality. J Natl Cancer Inst 84(20):1572-1575
24. Hiwatashi N, Morimoto T, Fukao A, Sato H, Sugahara N, Hisamichi S, Toyota T (1993) An evaluation of mass screening using fecal occult blood test for colorectal cancer in Japan: a case-control study. Jpn J Cancer Res 84(11):1110-1112

25. Saito H, Soma Y, Koeda J, Wada T, Kawaguchi H, Sobue T, Aisawa T, Yoshida Y (1995) Reduction in risk of mortality from colorectal cancer by fecal occult blood screening with immunochemical hemagglutination test. A case-control study. Int J Cancer 61(4):465-469

26. Zappa M, Castiglione G, Grazzini G, Falini P, Giorgi D, Paci E, Ciatto S (1997) Effect of faecal occult blood testing on colorectal mortality: results of a population-based case-control study in the district of Florence, Italy. Int J Cancer 73(2):208-210

27. Saito H, Soma Y, Nakajima M, Koeda J, Kawaguchi H, Kakizaki R, Chiba R, Aisawa T, Munakata A (2000) A case-control study evaluating occult blood screening for colorectal cancer with hemoccult test and an immunochemical hemagglutination test. Oncol Rep 7(4):815-819

28. Saito H (1996) Screening for colorectal cancer by immunochemical fecal occult blood testing. Jpn J Cancer Res 87:1011-1024

Publisher's note Springer Nature remains neutral with regard to jurisdictional claims in published maps and institutional affiliations. 